\title{
A FIGURAÇÃO DA AMAZÔNIA EM MAD MARIA, DE MÁRCIO SOUZA ${ }^{1}$
}

\author{
Wanessa de Oliveira COELHO \\ Marli Tereza FURTADO
}

\begin{abstract}
RESUMO
Este artigo discorre sobre a figuração da Amazônia no romance Mad Maria, de Márcio Souza. Verificam-se no romance, os avanços e recuos, em confronto com uma tradição, no retrato da Amazônia brasileira, além disso, investigam-se as técnicas de elaboração literária da obra. Importa-nos averiguar, em Mad Maria, a continuidade da quebra de paradigmas na configuração da Amazônia representada por Galvez, imperador do Acre, naquele contexto dos anos 70, bem como para assinalar Márcio Souza como um diferencial na literatura brasileira. Pois, diferente de outras narrativas que repetem o assunto e o estilo daquelas pautadas na economia local, principalmente a da borracha, soando até anacrônicas, Mad Maria ressignifica o assunto por meio de recursos como o humor, opondo-se as narrativas advindas da tradição literária que se estabeleceu a partir de À margem da História, de Euclides da Cunha. A base teórica utilizada para consolidar este artigo pode ser encontrada nos trabalhos de João Carlos de Carvalho - Amazônia revisitada: de Carvajal a Márcio Souza (2011) - de Allison Leão - Amazonas: natureza e ficção (2013)- e de Márcio Souza - A expressão amazonense: do colonialismo ao neocolonialismo (1977), entre outros
\end{abstract}

Palavras-chave: Amazônia. Mad Maria. Márcio Souza.

\begin{abstract}
This article discusses the figuration of Amazonia in the novel "Mad Maria", by Márcio Souza. In the novel, the advances and retreats, in contrast to a tradition, in the portrait of the Brazilian Amazon, in addition, the techniques of literary elaboration of the work are investigated. It is important to find out, in Mad Maria, the continuity of the breakdown of paradigms in the configuration of the Amazon represented by "Galvez, Imperador do Acre", in that context of the 70s, as well as to mark Márcio Souza as a differential in Brazilian literature. For, unlike other narratives that repeat the subject and style of those based on the local economy, especially that of rubber, sounding even anachronistic, Mad Maria re-signifies the subject by means of resources such as humor, opposing the narratives from the literary tradition which was established from Euclides da Cunha's "À margem da História". The theoretical basis used to consolidate this article can be found in the João Carlos de Carvalho - "Amazônia revisitada: de Carvajal a Márcio Souza" (2011) - Allison Leão - "Amazonas: natureza e ficção" (2013)- and in the Márcio Souza - "A expressão amazonense: do colonialismo ao neocolonialismo" (1977), among others.
\end{abstract}

Keywords: Amazon. Mad Maria. Márcio Souza.

1 Essa pesquisa faz parte do projeto "A Amazônia em narrativas dentro e fora do cânone: tradição e ruptura", sob orientação da Prof. ${ }^{a}$ Dra. Marlí Tereza Furtado.
2 Graduada em Letras pela Universidade Federal do Pará (UFPA).

3 Doutora em Teoria e História Literária pela Universidade Estadual de Campinas (UNICAMP). Realizou estágio pós-doutoral na Universidade Estadual do Rio de Janeiro (UERJ). Atualmente é professora ASSOCIADO III da Universidade Federal do Pará (UFPA)..
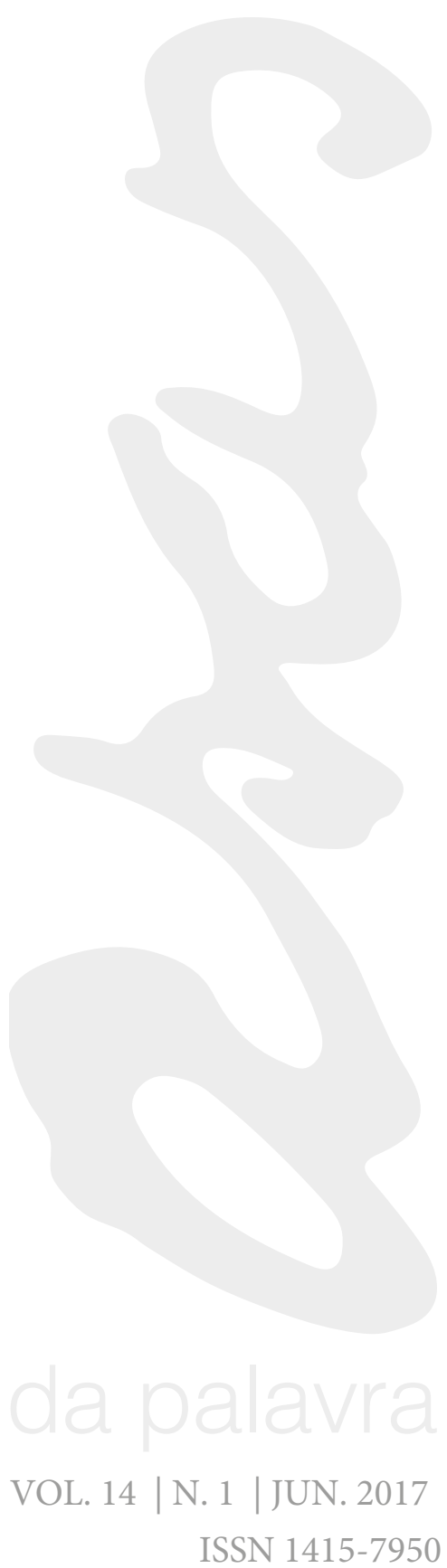


\section{INTRODUÇ̃̃O}

Na primeira metade do século XX, temos, na literatura brasileira, um grande número de autores que retrataram a Amazônia de acordo com o paradigma estabelecido a partir de À margem da História, de Euclides da Cunha, publicado em 1909, centrado na denúncia dos problemas sociais e ambientais gerados sobretudo pela exploração da borracha, em estilo grandiloquente.

Muitas dessas narrativas ficaram entre o relato e o estudo sobre a Amazônia, com pretensões literárias nem sempre atingidas. Outras avançaram e inovaram a forma de trabalhar ficcionalmente a região, dando novas perspectivas a autores subsequentes. Entre os escritores que criaram novos paradigmas literários, temos o marajoara Dalcídio Jurandir (1909/1979), que abriu com a obra Chove nos campos de Cachoeira, de 1941, a configuração da Amazônia paraense no ciclo Extremo Norte, concluído apenas em 1979, no décimo romance. O livro inicial do ciclo fraturou a tendência naturalista do romance da época e, por seu intimismo e técnica apurada, não foi muito bem compreendido, ficando enquadrado entre as obras regionalistas do período e Dalcídio Jurandir como um epígono dos autores da geração de 1930, dado que tem sido revisto nas últimas décadas.

Ao paradigma quebrado, somaram-se algumas obras em decênios posteriores, caso das elaboradas por Márcio Souza e Haroldo Maranhão, para citar apenas dois, aquele amazonense e este paraense. Curiosamente, no entanto, outros autores publicaram obras nos anos posteriores a 1960 ainda alinhados a uma visão da Amazônia naquele paradigma euclidiano que, entre os aspectos sociais, ressaltava o local antiteticamente, entre o Inferno e o Paraíso, enfatizando lhe o mistério e a força da natureza. Também é curioso o fato de alguns desses autores insistirem no retrato da Amazônia retomando o tema da economia da borracha, insistindo na técnica realista tradicional, beirando em muito o naturalismo literário.

Márcio Souza (Manaus, 1946), depois de algumas incursões teatrais nos inícios dos anos de 1970, em 1976 lançou a obra Galvez, imperador do Acre, a qual o projetou no cenário literário brasileiro exatamente pelo trabalho de reelaboração técnica de temas relativos à Amazônia. Dois anos depois, publicou o livro ensaístico A expressão amazonense: do colonialismo ao neocolonialismo no qual revela seu conhecimento sobre a região (mais especificamente seu estado de origem) e a literatura que a configura e que nela se configura. Dando continuidade ao seu projeto literário, editou em 1980 Mad Maria, narrativa em que conta a saga da construção da estrada de ferro Madeira-Mamoré, apropriando-se de fatos históricos, mas redimensionando-os pelo viés fictício e literário.

A literatura que retratava a Amazônia, nos anos entre 1950 a 1980, era composta por dois tipos de narrativas: as anacrônicas (persistiam numa tradição literária que figurava a Amazônia) e as que ressignificaram a concepção do espaço amazônico. Nessa última, encaixa-se a obra Mad Maria (1980), de Márcio Souza, como uma narrativa que confronta com uma tradição do retrato da Amazônia brasileira advinda do paradigma estabelecido por Euclides da Cunha.

Essa persistência da tradição estética no modelo euclidiano encontrava-se, entre outros, na "precariedade de referências literárias no século XIX sobre a Amazônia, vista até então quase que sob a ótica exclusiva de viajantes europeus ou dos seus epígonos" (CARVALHO, 2001, p.78), fazendo de Euclides da Cunha o grande desencadeador de uma linguagem própria para a região. Logo, Leão (2011) afirma que, haveria uma comunidade intelectual elitista que se enxergavam em Euclides da Cunha e passaria a tê-lo como molde.

$\mathrm{O}$ modelo euclidiano, que persistiu em narrativas posteriores, tem como base, como afirma Bosi (2015, p.333), "o peso de todos os determinismos, mas um olhar dirigido para a técnica e o progresso; uma linguagem de estilismo febril, mas sempre em função de realidades bem concretas". Desde cedo, Euclides da Cunha declinou de toda ficção que envolvesse a imaginação, o subjetivismo. Para ele, esse tipo de ficção "faz do escritor um minúsculo epítome do universo". Logo, sua cren- 
os homens" (SEVCENKO, 1999, p. 131). Junto a isso, a sólida erudição científica conduzia suas narrativas a um drama em que as personagens são os próprios agentes naturais. Euclides da Cunha "dota a natureza e os seus elementos de infinitas disposições e objetivos definidos" (SEVCENKO, 1999, p. 131).

A linguagem nas obras de Euclides da Cunha é totalmente coerente com seus ideais de evidenciar a superioridade da cultura científica e filosófica. Sevcenko (1999, p.132 e 135) afirma que os textos seguiam o mesmo estilo altamente elevado, metafórico e imagístico, "de comunicabilidade mediatizada, dotada de efeitos elocutivos, escoimado de clichês, rebarbativa, áspera, carregada, homogênea, praticamente sem variações sociolinguísticas, isenta de paródia ou prosopopeia". Nesse sentido, suas narrativas compunham "um bloco monolítico", sem flutuações que denotassem "a mudança do fluxo narrativo pela intervenção de um agente linguístico de nível social diverso daquele do narrador" (SEVCENKO, 1999, p. 132 -135).

É por meio desse estilo, que o escritor de À margem da história (1909) transpõe sua visão de mundo para sua obra: integração entre as regiões do Brasil, por meio da construção de estradas e ferrovias, o que contribuiria para o desenvolvimento da nação, alinhando o Brasil as grandes "civilizações", além de abrir espaços de comunicação entre as regiões possibilitando aos cidadãos que conhecessem seu país - principalmente a Amazônia. Isso contribuiria ainda para o desejo que o escritor tinha em que se atribuísse ao país o aspecto geral de uma população homogênea.

Era por meio dessas características que Euclides da Cunha retratava a região amazônica em suas obras. Para ele - no prefácio de Inferno Verde (1908) - a Amazônia era a terra misteriosa, desconhecida, grandiosa e quanto mais o homem tentasse desvenda-la, mais ela se tornaria turva. E a melhor forma de figurar a região numa obra seria não a alterar, mas copia-la. Por isso, o uso nas narrativas de uma linguagem mais especializada que decaia em uma interpretação fisiológica dos fenômenos naturais e sobrepunha o espaço amazônico sob as personagens.

Assim, na primeira metade do século XX, há um considerável número de escritores que prosseguem com essa perspectiva euclidiana na figuração da Amazônia na ficção, com uma temática, em sua maioria, que envolve a selva (desconhecida) e seu poder de sedução (possibilidade de enriquecimento), porém, em todos se encontram os elementos do mistério, do medo e da necessidade de desbravamento. Além disso, a floresta é configurada novamente como uma devoradora de homens, como uma personagem opressora, onde os mais fortes sobreviveriam, mas sempre sob o jugo, influência e determinaçãodo meio, do espaço, evidenciando o fisiológico e o patológico em detrimento do psicológico.

A tradição da literatura de ficção na Amazônia, desde o século XIX e em boa parte do XX, foi construída à base do descritivo, do terror e do êxtase diante da monumentalidade selvática e das personagens quase sempre imobilizadas em suas precárias condições psicológicas, onde um naturalismo às vezes tacanho procurava reforçar alguns fortes estereótipos. Dentre alguns textos mais famosos poderia citar [...] A voragem (1924), do colombiano José Eustasio Rivera e A selva (1930), do português Ferreira de Castro. Todos estavam inelutavelmente comprometidos, de uma forma ou de outra, com o restrito espaço sugestionado pela dicotomia paraíso/inferno. (CARVALHO, 2001, p. 15)

No entanto, como dito inicialmente, há, também nesse período, outra leva de escritores que não prosseguiram com o modelo euclidiano. É o caso de Márcio Souza cuja obra ficcional e ensaística vai de encontro com essa tradição do retrato da Amazônia brasileira estabelecido por Euclides da Cunha. No entanto, como afirma Carvalho (2001, p.161), Márcio Souza não deixou de dialogar com essa tradição amazônica, estabelecendo uma linha crítica e dialética "pelas coisas de sua região de forma bem mais original do que seus predecessores mais recentes". Em seu livro en- VOL. 14 | N. 1 | JUN. 2017 
saístico A expressão amazonense: do colonialismo ao neocolonialismo (1977, p.18), Márcio Souza confirma esse dialogo crítico com o passado:

Não foi fácil enfrentar uma bibliografia rara e uma documentação esparsa. Foi duro ler um romance de Álvaro Maia e não foi sem desagrado que se atravessou os promontórios de estilo do Barão de Sant'Anna Nery, nem as escarpas de Alberto Rangel. Foi preciso muita paciência para suportar as bobagens de Rodrigo Costa ou as aberrações de um João Leda. Mas foi uma trajetória fundamental e que mal começou. (SOUZA, 1977, p. 18).

A herança discursiva anterior, em Márcio Souza, "reúne os estilhaços metonímicos num só fôlego para tentar reencontrar o fio da meada perdido" (CARVALHO, 2001, p. 164). Logo, percebe-se, no escritor, uma consciência amazônica que permeia entre o combate, a resistência e a identidade, inseridas num processo de autorreconhecimento. Para Carvalho (2001, p. 164) "é uma reavaliação decisiva na inserção integrativa Amazônia-mundo, [...], pois uma diretriz ecológica, social, política e cultural se delineavam com tintas mais fortes".

A Amazônia morre pelos pecados dos brancos. Há 300 anos foi estabelecido um conflito que ameaça a integridade do grande vale. Um conflito que sentimos na pele e que revela diariamente nas ruas de nossas cidades, nas estradas que abrem o caminho do desmatamento. E nestes longos anos de conflito, nossa expressão artística parece recusar-se a reconhecer o perigo. Movidos pelas necessidades econômicas da empresa colonial, instigados pela ideologia da contra-reforma, os portugueses nos ensinara, a ver naquilo que há de mais originário, um inimigo desprezivel. Sistematicamente banida de nossa investigação artística, a cultura mais autêntica e viva da região recolheu-se para os arquivos etnográficos. O que era para ser esteio, viga-mestra e estrada luminosa, tornou-se curiosidade e folclore para especialistas. Poucos foram os que vislumbraram esse universo, a maioria preferiu a rota confortável do aniquilamento pela importação desenfreada de estéticas alienantes. A Amazônia índia é um anátema, um purgatório onde culturas inteiras se esfacelam no silêncio e no esquecimento. [...]. Vendados pela ideologia do progresso, ninguém toma em consideração esses filhos incômodos de uma humanidade primitiva, que impedem o caminho da sociedade até o lucro. [...] é necessário limpar o caminho de indios obstinados e preguiçosos. Pois nada mais obstinado e preguiçoso que essa gente que permitiu-se recusar através do tempo os favores da "civilização e do conforto" (SOUZA, 1977, p. 28-31).

Muito do que Márcio Souza discute em linhas fervorosas e em tom irônico em A expressão amazonense vai ser desenvolvido em Mad Maria (1980). Em um enredo dividido em dois cenários centrais: a Amazônia - mais especificamente Abunã, em Rondônia - e o Rio de Janeiro - capital do Brasil naquela época - Márcio Souza desconstrói com a polarização civilização e barbárie, mostrando que os conceitos são muito mais complexos do que se poderia supor.

Além disso, desmonta com o legado estilístico de Euclides da Cunha, que assolava as narrativas da região amazônica, inclusive seu modo de pensar a Amazônia como um ambiente que deveria ser domado por meio da racionalidade e do domínio científico o que pressuporia a implementação de uma civilização liberal- 
postura que quebre com toda essa tradição anterior.

Em Mad Maria, há uma configuração ficcional da Amazônia diferente daquela representada pelas narrativas da tradição literária na Amazônia. Apesar de comparada aos outros romances de Márcio Souza, ser uma narrativa que segue uma linha mais tradicional, de enfoque naturalista, que se compreende, segundo Carvalho (2001, p. 206), como "resgate do horror e do non-sense de um momento que continuava ecoando nos projetos faraônicos dos anos 70". A escolha por uma narrativa mais linear não implica nas superações alcançadas por Márcio Souza, em Mad Maria.

Dividida em cinco partes - "Ocidente express", "Arbeit macht frei”, "Um dia ainda vamos rir disso tudo", "Quando não puder resistir, relaxe e goze" e "As delícias da acumulação primitiva" - Mad Maria traz em sua estrutura narrativa alternância de cenas (mudança do espaço e das personagens) não delimitadas, a não ser por um duplo espaço entre os parágrafos, que exigem do leitor uma leitura mais atenta para compreender a entrada de outro cenário e outros personagens. Vejamos a mudança de cena entre os personagens Alonso e Collier:

Fora deste ambiente, Alonso estava muito nervoso, gritava com a sua voz forte, estimulando os índios, sem tirar os olhos do piano.

Tudo o que lhe vinha na cabeça, sempre, era esta sensação de estar deslocado do tempo. No período devoniano devia ser assim. E, quem sabe, também no período cambriano. (SOUZA, 1983, p. 16)

Nesse fragmento, Alonso está em Ribeirão com sua esposa Consuelo tentando desembarcar o quarto piano de corda vindo da Alemanha para satisfazer o desejo da mulher. Com a quebra de parágrafos advém a nova cena que é em Abunã, onde Collier reflete sobre o cenário em que está. A mudança de cena só é perceptível ao decorrer da leitura do episódio, em que há a inserção de novos elementos delimitando o espaço e as personagens.

Quanto à figuração da Amazônia na perspectiva tradicional, a primeira superação, em Mad Maria, está na ruptura da personagem dissolvida pela paisagem, onde o cenário amazônico personificado sobressalta as personagens, subjugando-as ao espaço. Sobre essa questão diz:

Tradicionalmente, as narrativas sobre a Amazônia, em face à grandiosidade do meio e da paisagem deslumbrante, tendem a privilegiar o espaço, em detrimento de outras categorias da ficção, como por exemplo, os personagens, que, se bem explorados, propiciariam uma visão adequada dos seres humanos. (KRUGER, 2001, p.09, apud LEÃO, 2011, p. 55).

Numa comparação entre o romance A selva (1930), de Ferreira de Castro, e Mad Maria, Milton Hatoum (1993, p. 113) afirma que a configuração da Amazônia neste transparece uma posição do narrador em que "não é a floresta em si (como sugere o narrador de Ferreira de Castro) que torna a vida degradante, e sim as condições de trabalho adversas num mundo diferente". Logo, no romance, de Márcio Souza, os conflitos internos e interpessoais vividos pelas personagens saltam a obra deixando em segundo plano o espaço amazônico. É uma clara provocação ao legado estilístico deixado por Euclides da Cunha.

Além disso, há uma linguagem totalmente descuidada daquela linguagem técnica imposta pelo modelo euclidiano, com a inserção do humor e da ironia. Essa tomada de posição irônica de Márcio Souza será sua grande arma para narrar uma história, pois por meio dela se dará a denúncia. Em Mad Maria, uma das vozes irônica e denunciante é a do engenheiro Collier. Vejamos dois episódios em que há um diálogo entre o engenheiro e Finnegan - jovem médico, de nacionalidade norte-americana: 
- É o senhor que está transformando isto aqui num hospício. [...]

- Eu? Sou eu por acaso o autor deste projeto estúpido? [...] Collier prosseguiu.

- Fui eu que inventei esta ferrovia que deverá levar um trem do nada a parte alguma, no meio do deserto? Ora, meu rapaz, no máximo eu posso ser um dos loucos, talvez o caso mais grave, mas assim mesmo um simples louco. (SOUZA, 1983, p.143)

- Fomos nós, Finnegan. Nós que colocamos elas aí, é para o que servimos. Para transformar em putas as mulheres nativas. - Você está exaltado sem razão, Collier. Chega de bobagens por hoje.

- Bobagens! São duas mulheres caripunas. [...]

- Elas é que se prostituíram, não nós.

- Você não passa de um frangote cheio de merda, Finnegan. Elas viviam aqui sem precisar de nós, e estão agora fodidas. Sabe o que é fodidas, Finnegan? [...]

- Você está reparando bem nelas, Finnegan. Já foram saudáveis e bonitas. Progrediram bastante. Devem ter sifilis, devem estar tuberculosas. [...] (SOUZA, 1983, p. 268)

No primeiro episódio, Finnegan discute com Collier, em Abunã, sobre a forma desumana de gerenciar o acampamento e o engenheiro rebate mostrando ao médico que os atos dele são simplórios ou chegam a ser até um reflexo da loucura maior que é aquele empreendimento. Noutro diálogo, o médico e o engenheiro estão no Porto de Santo Antônio, quando se deparam com duas mulheres em frente a um bordel prostituindo-se, no entanto, o que chama a atenção é o fato de as duas mulheres serem índias. Por meio da voz de Collier, há a denúncia do desastre que os grandes empreendimentos trouxeram àquela localidade.

Nesse ponto, por meio das denúncias, Márcio Souza, em Mad Maria, desconstrói mais um aspecto da herança deixada por Euclides da Cunha, o falso discurso de que a integração das regiões por meio da abertura de vias, trazendo grandes empreendimentos ao Brasil, possibilitaria o desenvolvimento do país, aproximando-o das grandes potências. Esse falso discurso foi exposto na voz de Farquhar, o empresário que comandava a Companhia:

Agora, quando estivermos operando com a ferrovia, todos os perigos desaparecerão, e o que é mais importante, os prejuízos não mais ocorrerão. [...] a ferrovia estará enriquecendo o povo brasileiro com lucros adicionais de milhões de libras esterlinas. [...] Derrubamos árvores seculares, enfrentamos e civilizamos selvagens que mourejavam na idade da pedra. [...] oferecemos as melhores condições de trabalho numa área inóspita e bárbara. (SOUZA, 1983, p. 311)

Porém, o que estava por detrás de grandes empreendimentos como a construção da via férrea Madeira-Mamoré não era o progresso da nação e sim grandes perdas financeiras, ambientais e socioculturais, bem como o enriquecimento de empresários. Ou seja, o símbolo da modernidade e progresso, o trem, não trouxe a "civilização" capitalista para a floresta amazônica - como pensava Euclides da Cunha que tinha na Transacreana o sonho de uma aliança civilizadora, jogando "sobre os ombros da Amazônia a responsabilidade de construir a sua própria história, de uma gênese sempre pronta a se inaugurar diante de qualquer sinal civilizatório" (CARVALHO, 2001, p. 208) - mas sim a barbárie capitalista. Novamente, é a voz de Collier que denuncia isso: 
- Nós somos bárbaros, Finnegan. [...]

- Não concordo. Você e eu trabalhamos pelo progresso.

- Um caralho! Quer saber o que significa para mim o progresso? Uma política de ladrãos enganando países inteiros. Birmânia, Índia, África, Austrália, os nossos alvos. (SOUZA, 1983, p. 256-257)

Em Mad Maria, Márcio Souza trabalha no enredo a desconstrução dos conceitos sobre civilização e barbárie. Esses conceitos são desmontados por meio das ações das personagens, que foram criados em ambientes urbanizados - os alemães, o Collier, Finnegan, ministro Seabra, entre outros - porém suas atitudes são desumanas. Enquanto no índio, que viu seus familiares sendo mortos pelos ditos "civilizados", sobra humanidade.

O narrador onisciente é quem dá voz ao índio: "O seu povo era muito manso e tinha orgulho de ser melhor e mais bem organizado que os civilizados [...] os velhos diziam sempre que de todas as tribos os civilizados eram os mais bravos e perigosos porque matavam sem nenhum motivo [...]" (SOUZA, 1983, p. 67). Em A expressão amazonense, Márcio Souza (1977, p. 37) revela sua concepção sobre os conceitos de civilização e barbárie:

Eis porque somente a falácia ou a ignorância podem ainda sustentar os velhos conceitos de civilização e barbárie. A manutenção desses conceitos revela preconceitos de classe e interesses inconfessáveis. É preciso voltar para a Amazônia e, reconhecendo a sua agonia, procurar restaurar a sua verdade por um consciente trabalho de solidariedade. Não podemos mais permitir que a região seja considerada uma categoria do exótico; desta maneira evitaremos que sua exploração também se torne um desfrute. Um conhecimento mais aprofundado das culturas autóctones derruba por terra as velhas pretensões etnocentristas. Como classificar de bárbaras culturas que produziram páginas literárias como as que estão reunidas por Nunes Pereira em Moronguetá, um Decameron indígena? Como classificar de primitiva uma civilização que ainda reúne o dionisíaco e o apolíneo numa só força criadora? Entre os índios não há separação entre trabalho manual e intelectual, entre poeta e filósofo, entre vida e ser. Em contrapartida, como outorgar o estatuto de civilização superior a quem fabrica campos de concentração e reduz metade da população da Terra ao estado de inanição? (SOUZA, 1977, p. 37).

Nesse quadro de tensões, dois episódios chamam atenção pelas cenas de horror, evidenciando a concepção defendida por Márcio Souza sobre quem seriam, na verdade, os civilizados e os bárbaros. O primeiro episódio é narrado no dia em que "os civilizados" chegaram à aldeia do índio caripuna: "Os brancos civilizados não gostavam de acordos e preferiam roubar as mulheres e atirar nos homens. Um dia tentaram roubar a sua pequena tacuatepes mas ela não queria ir e se debateu e gritou com tanta fúria que um civilizado abriu ela com golpe que saía do pescoço e acabava entre as pernas dela" (SOUZA, 1983, p. 68). O segundo é quando o índio caripuna é capturado pelos homens que trabalhavam na construção da via férrea:

Os civilizados estavam excitados e batiam nesse, batiam com força e ele gritava. Vomitava sangue e os beiços estavam partidos e inchados e mal podia abrir os olhos. Aconteceu então o pior. Os civilizados seguraram ele esticado no chão e colocaram os dois braços dele sobre a um dormente. Um civilizado 
pegou o machado e decepou na altura do antebraço as suas mãos. (SOUZA, 1983, p. 85).

O índio caripuna sobrevive com a chegada do engenheiro Collier que interrompe a continuação do massacre físico, em contrapartida o índio sofre a aniquilação dos últimos resquícios de sua cultura. O médico Finnegan "batiza-o" com um nome americano e cristão, Joe, variação do nome do profeta bíblico Joel. E começa o processo de aculturação. O índio, agora chamado Joe, aprende a língua inglesa, os costumes dos "civilizados" e começa a entender como funciona o sistema capitalista: "A primeira lição importante que aprendeu na enfermaria foi a ter senso de propriedade. Seguindo esta lição, compreendeu que a propriedade significava possuir coisas e que estas não surgiam do nada" (SOUZA, 1983, p. 263).

Márcio Souza mostra, em Mad Maria, que a floresta não é o inferno, os homens "civilizados" é que o trouxeram para lá. Em nome do progresso e da modernidade na selva, dizimaram tribos indígenas, destruíram a natureza, mataram trabalhadores de várias nacionalidades que viviam em condições sub-humanas. A representação da modernidade na selva era a locomotiva Mad Maria, tudo em Abunã girava entorno da "Grandiosa, Mad Maria", a "rainha de ferro" "resistindo onde muitos homens fortes e duros estavam se deixando abater", ela "comandava a todos com os seus caprichos e com a sua indiferença" (SOUZA, 1983, p. 140).

Para Carvalho (2001, p. 225) "a locomotiva atua como uma protagonista irradiadora de um campo muito mais complexo de temas, gerando as outras personagens (protagonistas, cada um, em seu próprio drama)". A travessia que se dá não é a ligação Madeira-Mamoré, mas sim a perda da humanidade, do caráter irreversível, ninguém poderia se manter íntegro. Isso se revela principalmente em Finnegan e se autoafirma em personagens como Collier e Farquhar:

- Chega, Finnegan. Assim você vai acabar com a minha mão de obra, rapaz.

Três homens se contorcem no chão, malferidos, e seis morreram ao receber a descarga de winchesters. [...] Finnegan passa a mão no queixo dolorido e olha para o engenheiro. Collier sacode a cabeça e Finnegan vê naquele gesto uma ponta de ironia. Pouco se importa, a ironia, deboche e a irreverência de Collier já não mais lhe tocavam, o que era uma pena. [...] O máximo que ele podia sentir agora era cansaço, muito cansaço, pois só os bobos podiam se importar com alguma coisa além da arte de ficar vivo. (SOUZA, 1983, p. 344)

Finnegan ao final da narrativa não é mais o mesmo, não é mais um contraste de Collier. O misantropismo do engenheiro conseguiu exterminar com últimos resquícios de idealismo do médico. Ao final, numa retomada de cena, mas que agora não é Collier quem ordena o fuzilamento dos trabalhadores, mas sim Finnegan, que a principio, ao chegar a Abunã, repudiava as atitudes do engenheiro. Para Carvalho (2001, p. 215) "nenhum outro artifício pode disfarçar o ponto a que cada um chegou ou chegará, restando apenas o lamento de um narrador que também percebe o esvaziamento de sua voz. [...] Completa-se, portanto, o percurso cíclico desse avassalador romance".

\section{CONCLUSÃO}

Averiguou-se, portanto, a continuidade da quebra de paradigmas na configuração da Amazônia em Mad Maria. Márcio Souza desenvolve, no romance, sua concepção sobre a região. Na narrativa, retira a floresta amazônica como foco ela não atuará mais como personagem, mas como cenário - e visa nas personagens, mostrando uma série de fatos e fatores que independem do meio e têm como único 
responsável a ação humana. Desse modo, a antinomia inferno e paraíso, estabelecido por uma tradição estética na Amazônia, é evidentemente uma visão do colonizador, pois é ele quem constrói e leva o inferno àquela região.

Ademais, utiliza recursos estilísticos não utilizados por escritores que permaneceram naquela tradição: a ironia e o humor. São esses dois recursos que dão uma nova roupagem à escolha do autor por um enfoque naturalista. Para Carvalho (2001, p. 209), "o naturalismo das cenas, ou a bestialização das personagens, segue de perto a própria opção estética do autor, o de um retrato dolorido de uma época, e de uma desumanização, no fundo, de raiz bastante humana". É o humor que trará leveza ao romance, contrariando as narrativas realistas e a aversão à sátira de Euclides da Cunha que dizia "eu não gracejo nunca", "não façam rir ninguém" (SEVCENKO, 1999, p. 134). E a ironia será o recurso utilizado para a denúncia que se alterna entre as vozes das personagens e do narrador onisciente.

Por fim, outra ruptura com aquela tradição é a desconstrução da visão de Euclides da Cunha sobre a temática do progresso do país, do qual se daria por meio da modernização, junto à ligação das regiões, que deveria culminar numa utópica homogeneização do país. O enredo de Mad Maria mostra a outra face desse progresso que não levava em consideração as particularidades de cada região, não respeitando a natureza e muito menos as tribos indígenas. Mostrando que nunca se quis compreender a floresta amazônica e sim submetê-la aos caprichos de um capitalismo que estava instalando-se.

\section{REFERÊNCIAS}

BOSI, Alfredo. História concisa da literatura brasileira. 50. ed. São Paulo: Cultrix, 2015.

CARVAlHO, João Carlos de. Amazônia revisitada: de Carvajal a Márcio Souza. São José do Rio Preto: [s.n.], 2001.

CUNHA, Euclides da. Um paraíso perdido: reunião de ensaios amazônicos. Brasília: Senado Federal, Conselho Editorial, 2009.

HARDMAN, Francisco Foot. Trem fantasma: a modernidade na selva. São Paulo: Companhia das Letras, 1988.

HATOUM, Milton. A natureza como ficção. In: Grossman, Judith et all. O espaço geográfico no romance brasileiro. Salvador: Fundação Casa de Jorge Amado, 1993.

LEÃO, Allison. Amazonas: natureza e ficção. São Paulo: Annablume; Manaus: FAPEAM, 2011;

SEVCENKO, Nicolau. Literatura como missão: tensões sociais e criação cultural na Primeira República. São Paulo: Brasiliense, 1999.

SOUZA, Márcio. A expressão amazonense: do colonialismo ao neocolonialismo. São Paulo: Alfa-Omega, 1977.

. Mad Maria - 2a ed. Rio de Janeiro: Civilização Brasileira, 1983; 